\title{
BMJ Open Interprofessional education in geriatric medicine: towards best practice. A controlled before-after study of medical and nursing students
}

\author{
Sanja Thompson (D) , ${ }^{1,2}$ Kiloran Metcalfe, ${ }^{2}$ Katy Boncey, ${ }^{1}$ Clair Merriman, ${ }^{3}$ \\ Lorna Catherine Flynn, ${ }^{4}$ Gaggandeep Singh Alg (10 , ${ }^{1}$ Harriet Bothwell, ${ }^{1}$ \\ Carol Forde-Johnston, ${ }^{3}$ Elizabeth Puffett, ${ }^{3}$ Caroline Hardy, ${ }^{3}$ Liz Wright, ${ }^{1}$ \\ James Beale ${ }^{1}$
}

To cite: Thompson S, Metcalfe K, Boncey K, et al. Interprofessional education in geriatric medicine: towards best practice. A controlled before-after study of medical and nursing students. BMJ Open 2020;10:e018041. doi:10.1136/ bmjopen-2017-018041

- Prepublication history and additional material for this paper are available online. To view these files, please visit the journal online (http://dx.doi. org/10.1136/bmjopen-2017018041).

Received 18 January 2019

Revised 31 July 2019

Accepted 23 August 2019

Check for updates

(c) Author(s) (or their employer(s)) 2020. Re-use permitted under CC BY-NC. No commercial re-use. See rights and permissions. Published by BMJ.

${ }^{1}$ Geratology department, John Radcliffe Hospital, Oxford, UK

${ }^{2}$ Medical Sciences Division, University of Oxford, Oxford, UK ${ }^{3}$ Faculty of Health and Life Sciences, Oxford Brookes University, Oxford, UK

${ }^{4}$ Nuffield Department of Surgical Sciences, University of Oxford, Oxford, UK

Correspondence to

Sanja Thompson;

sanja@doctors.org.uk

\section{ABSTRACT}

Objectives To investigate nursing and medical students' readiness for interprofessional learning before and after implementing geriatric interprofessional education (IPE), based on problem-based learning (PBL) case scenarios. To define the optimal number of geriatric IPE sessions, the size and the ratio of participants from each profession in the learner groups, the outcomes related to the Kirkpatrick four-level typology of learning evaluation, students' concerns about joint learning and impact of geriatric IPE on these concerns. The study looked at the perception of roles and expertise of the 'other' profession in interprofessional teams, and students' choice of topics for future sessions. Students' expectations, experience, learning points and the influence on the understanding of IP collaboration, as well as their readiness to participate in such education again were investigated.

Design A controlled before-after study (2014/2015, 2015/2016) with data collected immediately before and after the intervention period. Study includes additional comparison of the results from the intervention with a control group of students. Outcomes were determined with a validated 'Readiness for Interprofessional Learning' questionnaire, to which we added questions with free comments, combining quantitative and qualitative research methods. The teaching sessions were facilitated by experienced practitioners/educators, so each group had both, a clinician (either geratology consultant or registrar) and a senior nurse.

Participants 300 medical, 150 nursing students.

Setting Tertiary care university teaching hospital.

Results Analysis of the returned forms in the intervention group had shown that nursing students scored higher on teamwork and collaboration post-IPE $(\mathrm{M}=40.78, \mathrm{SD}=4.05)$ than pre-IPE $(\mathrm{M}=34.59, \mathrm{SD}=10.36)$-statistically significant. On negative professional identity, they scored lower post-IPE $(\mathrm{M}=7.21, \mathrm{SD}=4.2)$ than pre-IPE $(\mathrm{M}=8.46$, $\mathrm{SD}=4.1$ - - statistically significant. The higher score on positive professional identity post-IPE $(M=16.43, S D=2.76)$ than pre-IPE ( $M=14.32, S D=4.59)$ was also statistically significant. Likewise, the lower score on roles and responsibilities post-IPE $(\mathrm{M}=5.41, \mathrm{SD}=1.63)$ than pre-IPE $(\mathrm{M}=6.84, \mathrm{SD}=2.75)$.
Strengths and limitations of this study

- This is a novel evidence regarding good practice for geriatric undergraduate interprofessional education (IPE) derived from a large unselected (inclusive) cohort of medical and nursing students.

- A controlled before-after study, with students randomly assigned to the intervention and control groups, combining quantitative and qualitative research evaluation.

- The number of nursing students was smaller, so the control group consisted of only medical students.

- The nursing students had more clinical experience than the medical students at the time of the geriatric IPE.

- Medical students were not divided by their entry level, they were mixed from graduate-entry and standard-entry medicine course.

Medical students scored higher on teamwork and collaboration post-IPE ( $\mathrm{M}=36.66, \mathrm{SD}=5.1)$ than pre-IPE $(\mathrm{M}=32.68, \mathrm{SD}=7.4)$-statistically significant. Higher positive professional identity post-IPE $(\mathrm{M}=14.3, \mathrm{SD}=3.2)$ than pre-IPE $(M=13.1, S D=4.31)$ - statistically significant. The lower negative professional identity post-IPE $(M=7.6$, $S D=3.17)$ than pre-IPE $(M=8.36, S D=2.91)$ was not statistically significant. Nor was the post-IPE difference over roles and responsibilities ( $\mathrm{M}=7.4, \mathrm{SD}=1.85)$, pre-IPE $(\mathrm{M}=7.85, \mathrm{SD}=2.1)$.

In the control group, medical students scored higher for teamwork and collaboration post-IPE ( $\mathrm{M}=36.07$, $\mathrm{SD}=3.8)$ than pre-IPE $(\mathrm{M}=33.95, \mathrm{SD}=3.37)$ - statistically significant, same for positive professional identity post-IPE $(M=13.74, S D=2.64)$, pre-IPE $(M=12.8, S D=2.29)$, while negative professional identity post-IPE $(\mathrm{M}=8.48, \mathrm{SD}=2.52)$, pre-IPE $(M=9, S D=2.07)$, and roles and responsibilities post-IPE $(\mathrm{M}=7.89, \mathrm{SD}=1.69)$, pre-IPE $(\mathrm{M}=7.91, \mathrm{SD}=1.51)$ shown no statistically significant differences. Student concerns, enhanced understanding of collaboration and readiness for future joint work were addressed, but not understanding of roles. 
Conclusions Educators with nursing and medical backgrounds delivered geriatric IPE through case-based PBL. The optimal learner group size was determined. The equal numbers of participants from each profession for successful IPE are not necessary. The IPE delivered by clinicians and senior nurses had an overall positive impact on all participants, but more markedly on nursing students. Surprisingly, it had the same impact on medical students regardless if it was delivered to the mixed groups with nursing students, or to medical students alone. Teaching successfully addressed students' concerns about joint learning and communication and ethics were most commonly suggested topics for the future.

\section{INTRODUCTION}

The recommendations for interprofessional education (IPE) from professional accreditation bodies for healthcare students ${ }^{12}$ relates closely to the specialty of Geriatrics, as being delivered by interprofessional (IP) teams. WHO considers IPE to be "key to improving global health outcomes and to the global health workforce crisis', ${ }^{3}$ the Institute of Medicine recommends education in IP team care for health professionals, while IP team-based practice is recognised as an essential model in particularly for complex medical issues. ${ }^{45}$

IPE is believed to prepare practitioners for effective teamwork, which is particularly important for the personcentred, collaborative geriatric care,${ }^{6}$ with patients often presenting with complex issues, necessitating whole-team involvement in finding comprehensive solutions, as individual team members' knowledge from the training of only one discipline is often not sufficient. ${ }^{7}$ This confirms the consensus among geriatricians (and other healthcare professionals) that the provision of good care for all older patients through only autonomous practice is not achievable. ${ }^{8}$ The theoretical basis for IPE is known. ${ }^{9}$ Nevertheless, IPE in geriatric medicine still lacks established standards and best practice, for example, regarding the optimal timing and delivery, or which IPE models are most effective for addressing specific problems. ${ }^{10-14}$ It is well known that one of the difficult things to learn in the healthcare provision process is the timing and the way of communication among healthcare providers, both for teams and or individuals. ${ }^{8}$ Taking into consideration that professional identity starts early in the training, the development and implementation of geriatric IPE modules are not surprising; ${ }^{15}{ }^{16}$ however, the literature on geriatrics IPE at the undergraduate and postgraduate level is still sparse. The geriatric IPE models address various problems regarding complex geriatric patients, including problems in palliative geriatrics, comprehensive geriatric assessment, a clinic-based consultation or a clarification of role confusion among members of the teams. ${ }^{16-19}$ Such education is based on the presumption that skills for interprofessional care are not acquired 'naturally' before graduation, nor are they necessarily acquired with ongoing clinical experience. ${ }^{80-23}$ There are various IPE models, even including some based on e-learning courses. ${ }^{21-23}$

Previous work on IPE has shown that it can have advantages in improving staff morale and patient outcomes and that the various IP teams develop in different ways (eg, differences in surgical or geriatrics teams), the assumption is that certain teams in healthcare settings attract certain personality types, but who share unique goals and values regarding care or specific issues in the patients. ${ }^{81214}$ Some of the common core competencies outlined by the health professionals (regardless of their specialty) being most important for the effective collaborative practice, are the role understanding and communication. ${ }^{24}$

As a step to meet the need for geriatric IPE at the undergraduate level, without compromising the integrity of uniprofessional medical and nursing education, ${ }^{25}$ a geriatric IPE was developed for medical and nursing students and run as a controlled before-after study in Oxford (Medical School, NHS, Oxford University Hospitals Foundation Trust and Brookes University). Set in a tertiary care university-based teaching hospital (John Radcliffe Hospital), during the 2014/2015 and 2015/2016 academic years, a study aimed to identify an effective way of delivering undergraduate geriatric IPE.

\section{METHODS}

Data were obtained using mixed-methods (quantitative or qualitative), due to the complexity of assessing IPE and possible confounding factors that could affect the validity of the results when evaluating the impact of IPE. The study was conducted as a controlled before-after study, with data collected immediately before and after the intervention period. It was decided at the planning stage that a validated scale should be used for the evaluation. Use was made of the Readiness for Interprofessional Learning Scale (RIPLS) ${ }^{26}$ in a modified form, in order to assess the readiness of healthcare students to engage in shared learning activities which consisted of four subscales: teamwork and collaboration, positive professional identity, negative professional identity and roles and responsibilities. ${ }^{27}$ Students participating completed the modified RIPLS preintervention and postintervention in both intervention and control groups, including a number of open-ended questions that we added to the questionnaire to allow students to expand on their experiences in the teaching session and to add to our understanding of the geriatric IPE (online supplementary files $1 ; 2)$.

\section{Student cohort}

The workshops were delivered to medical students from Oxford University Medical School and nursing students from Oxford Brookes University. Medical students were at the beginning of their 6-week clinical attachment, mixed from Year 4 of the 6-year course and Year 2 of the 4-year graduate entry course, preceding their clinical exposure to geriatrics-related problems. The researchers did not know the medical students' affiliation. All medical students also attended the introduction course to geriatrics and a communication skills workshop (addressing dementia/delirium and challenging behaviours in older patients) during that teaching week. ${ }^{28}$ Nursing students 
were recruited from Years 2 and 3 (due to the significantly smaller number of nursing students in clinical placements at the JR Hospital in Oxford, compared with medical students) of their 3-year course. The nursing students had already cared for older patients during previous clinical placements throughout their course, their curriculum covering a life-span approach to theory and practice. None of the students had any specific teaching in interprofessional collaboration prior to this session.

Eighty medical students (two groups of 40 from each academic year) could not be matched with nursing students, so acted as the control group. The decision about the grouping of students to the intervention and the control groups was determined exclusively by the number of students from both institutions and their availability for clinical rotations (students allocations to the rotations was the routine administration decision by both University organisations). So, all students were randomly assigned to the intervention and control groups, this being determined by the separate timetables from their respective institutions issued before this teaching. The formation of control groups was determined by the available medical students who could not be matched with the nursing students on the JR Hospital site due to their numbers.

\section{Workshops}

The sessions were based on problem-based learning (PBL) with standardised case-scenarios relevant to geriatric practice mapped to the learning objectives on the Joint Royal Colleges of Physicians Training Board geriatric medicine curriculum ${ }^{29}$ mirroring situations encountered by clinicians/nurses, requiring an IP collaborative approach (online supplementary file 3). ${ }^{1430}$

Each workshop comprised approximately 30-45 min of introduction by a senior clinician and a nurse, followed by 2 hours of self-directed learning and a session facilitated jointly by nurses and geriatricians, aiming to facilitate professional socialisation ${ }^{30} 31$ and collaboration through constructive discussion about the skills required from each profession when caring for older patients. It aimed to build higher level skills (such as reflection by students/facilitators) and cooperative learning ${ }^{4}$ while problem-solving these cases. A short power point presentation contained several slides explaining the venues, the structure of the sessions and the names of the facilitators designated for each group. The presentation also included basic information about one case (as an example) that students will work on, with few images related to the themes of the cases (eg, patient's hands with severe psoriasis after treatment refusal to illustrate self-neglect/abuse). Students were encouraged to discuss all cases in a way they felt was important from their professional point, including the initial nursing and medical management steps (eg, patient hygiene, $\mathrm{ABCD}$ ), main nursing and medical concerns in the continuation of care for each case, how to approach the shared role needed in the management of these patients-the complementary roles or how to plan early interdisciplinary involvement.
The group was then split to accommodate similar numbers of attendees according to their roles as medic or nurse, to ensure an even spread of disciplines. Each IPE subgroup never had more than 10 members to aid discussion. Each student received a typed worksheet with all case scenarios and several suggested questions to help discussion of each case, related to the problems relevant to both professional groups. Students were allocated an hour to work through the case scenarios on their own, without facilitators and were expected to complete most of the work themselves first. The groups had another hour allocated afterwards with two lead facilitators from each profession (a geriatrician and a senior nurse), in order to discuss these cases. The input from them was to encourage further discussion about potential problems when managing these cases, about the roles of each professional and to hear their experience with these or similar cases. Both facilitators reflected on their own experience of such cases/situations. The mixed groups could discuss the scenarios with the 'other' profession during both sessions-something that was possible for the control group in its final session with the facilitators, with the emphasis on each profession's contribution/ collaboration/role in the management of given cases.

\section{Evaluation}

The potential problems if using only a single quantitative or qualitative method for assessing the learning outcomes of IPE are well known, ${ }^{12}{ }^{32-34}$ so the assessment was carried out with mixed (quantitative and qualitative) methods, anonymously, on a voluntary basis. The quantitative analysis was conducted with a validated modified questionnaire, 'RIPLS' which assesses participants across four subscales (online supplementary files 1, 2). ${ }^{26} 2732$ Additionally, we created extra questions with free comments addressing students' perception of the roles of nurses/ doctors, their concerns about IP working; curricular topic suggestions for future IPE sessions; students' expectations, the type of experiences encountered and the impact of the workshop on their understanding of collaboration and their ability to work together in future. The questionnaire was administered before and after the workshop.

Data were transcribed by KM, KB, ST and $\mathrm{HB}$, on a Microsoft Excel spreadsheet and the results from RIPLS were analysed with a Wilcoxson signed-rank test by LCF. For the open-ended questions, all responses were transcribed by ST, HB to a spreadsheet and coded and analysed by LCF. LCF who is a non-specialist from the wider team and experienced qualitative researcher analysed all free-text responses. ${ }^{35}$ Qualitative data from the free-text questionnaire were analysed using NVivo V.10. Of note, 300 medical and 150 nursing students participated.

\section{RESULTS}

In quantitative assessment, we compared mean RIPLS subscale scores with a Wilcoxson signed-rank test to 
All students

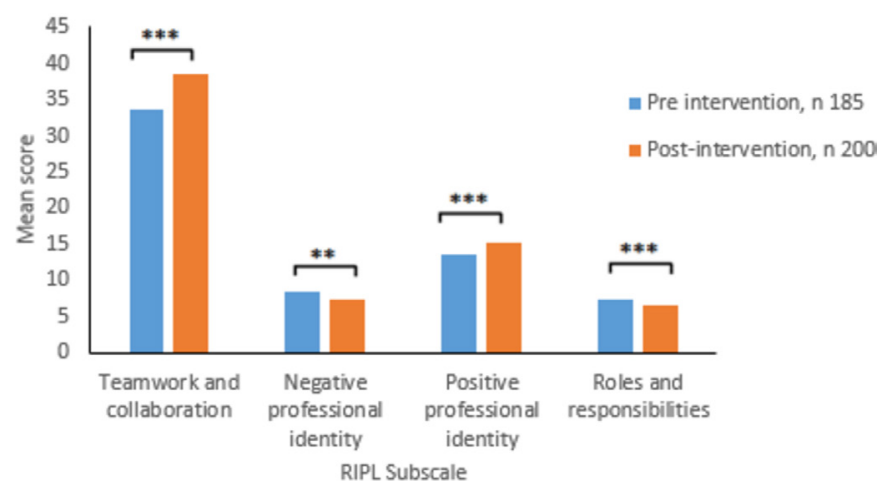

Figure 1 Results for all nursing and medical students showed post-IPE statistically significant improvements in all four RIPLS subscales. IPE, interprofessional education; RIPLS, readiness for interprofessional learning.

determine if the IPE intervention had changed students' attitudes.

When all the results from all students are analysed for the intervention groups for the students who returned their forms (185 preintervention and 200 postintervention), the statistically significant improvements post-IPE was found in all four RIPLS subscales, due mainly to nursing students responses: teamwork and collaboration, positive professional identity, roles and responsibilities and negative professional identity (figure 1).

But, when a t-test is applied to the forms from the nursing students only (preintervention 91, postintervention 95 returned forms, figure 2) it showed, on average, that participants scored higher on teamwork and collaboration post-IPE $(\mathrm{M}=40.78, \mathrm{SD}=4.05)$ than pre-IPE $(\mathrm{M}=34.59, \mathrm{SD}=10.36)$. This difference was statistically significant $(t(-5.32)=115.86, \mathrm{p}=0.000)$. Participants scored lower on negative professional identity after IPE $(\mathrm{M}=7.21, \mathrm{SD}=4.2)$ than before it $(\mathrm{M}=8.46, \mathrm{SD}=4.1)$. This difference was statistically significant $(t(2.06)=183.94$, $\mathrm{p}=0.041$ ). Participants on average scored higher on

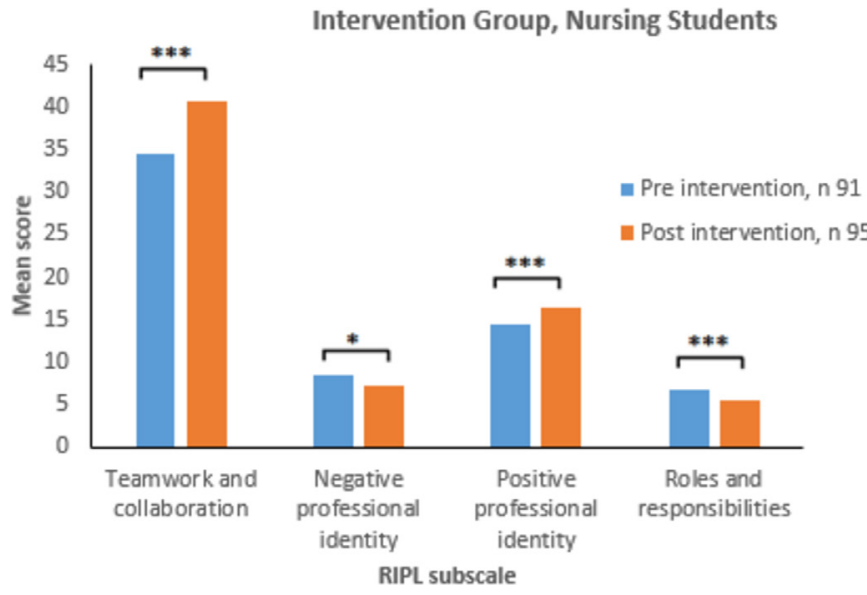

Figure 2 The nursing students in the intervention group showed post-IPE statistically significant improvements in all four RIPLS subscales. IPE, interprofessional education; RIPLS, readiness for interprofessional learning.

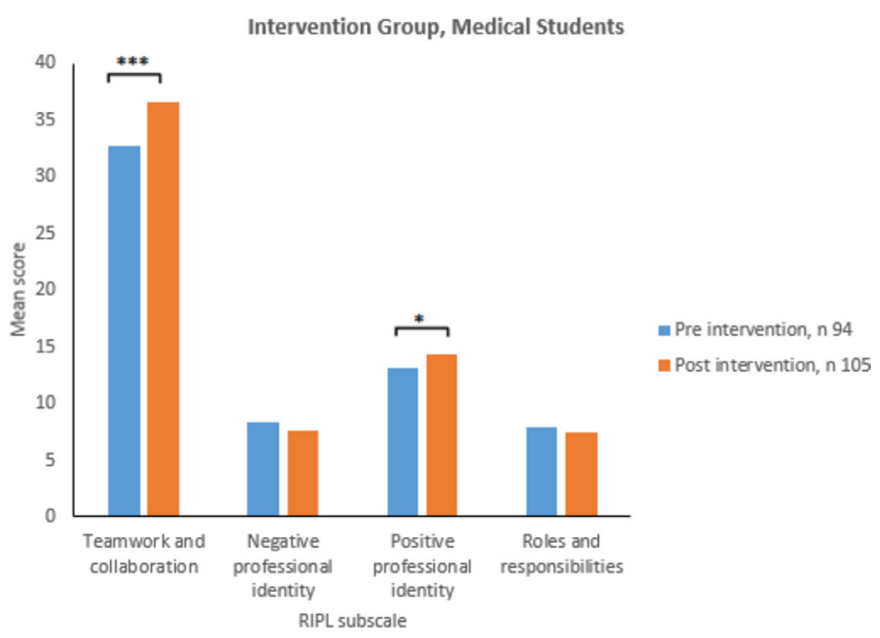

Figure 3 Post-IPE, the medical students in the intervention group showed statistically significant improvements in two RIPLS subscales: teamwork and collaboration and positive professional identity. IPE, interprofessional education; RIPLS, readiness for interprofessional learning.

positive professional identity $(\mathrm{M}=16.43, \mathrm{SD}=2.76)$ post-IPE than prior to the IPE session $(\mathrm{M}=14.32, \mathrm{SD}=4.59)$. This difference was statistically significant $(t(-3.78)=146.2$, $\mathrm{p}=0.000$ ). On average, participants scored lower on roles and responsibilities after IPE $(\mathrm{M}=5.41, \mathrm{SD}=1.63)$ than before it $(\mathrm{M}=6.84, \mathrm{SD}=2.75)$. This difference was statistically significant $(t(4.27)=145.14, \mathrm{p}=0.000)$.

As shown in figure 3 , the analysis of the returned forms from the medical students from the intervention group analysis (preintervention 94, postintervention 105 returned forms) had revealed that they had scored higher on teamwork and collaboration post-IPE (M=36.66, $\mathrm{SD}=5.1)$, than pre-IPE $(\mathrm{M}=32.68, \mathrm{SD}=7.4)$. This difference was statistically significant $(t(-4.36)=162.43, \mathrm{p}=0.000)$. Also, these students on average scored higher on positive professional identity $(\mathrm{M}=14.3, \mathrm{SD}=3.2)$ post-IPE than prior to the IPE session $(\mathrm{M}=13.1, \mathrm{SD}=4.31)$. This difference was statistically significant $(t(-2.24)=197, \mathrm{p}=0.026)$. However, these medical students scored lower on negative professional identity after IPE $(\mathrm{M}=7.6, \mathrm{SD}=3.17)$ than before it $(\mathrm{M}=8.36, \mathrm{SD}=2.91)$. This difference was not statistically significant $(t(1.69)=197, \mathrm{p}=0.092)$, and there was little difference in post-IPE for roles and responsibilities after IPE $(\mathrm{M}=7.4, \mathrm{SD}=1.85)$ than before it $(\mathrm{M}=7.85$, $\mathrm{SD}=2.1)$. This difference was not statistically significant $(t(1.58)=197, \mathrm{p}=0.116)$.

The results for the control group of students who returned the forms (preintervention 74, postintervention 54) are shown in figure 4. Post-IPE results had shown the significant improvements in the teamwork and collaboration $(\mathrm{M}=36.07, \mathrm{SD}=3.8)$, than pre-IPE $(\mathrm{M}=33.95, \mathrm{SD}=3.37)$. This difference was statistically significant $(\mathrm{t}(-3.35)=126$, $\mathrm{p}=0.001)$. The control group had scored higher on positive professional identity subscales $(\mathrm{M}=13.74, \mathrm{SD}=2.64)$ post-IPE than prior to the IPE session $(\mathrm{M}=12.8, \mathrm{SD}=2.29)$. This difference was statistically significant $(t(-2.16)=126$, $\mathrm{p}=0.033$ ). 


\section{Control Group (medical students only)}

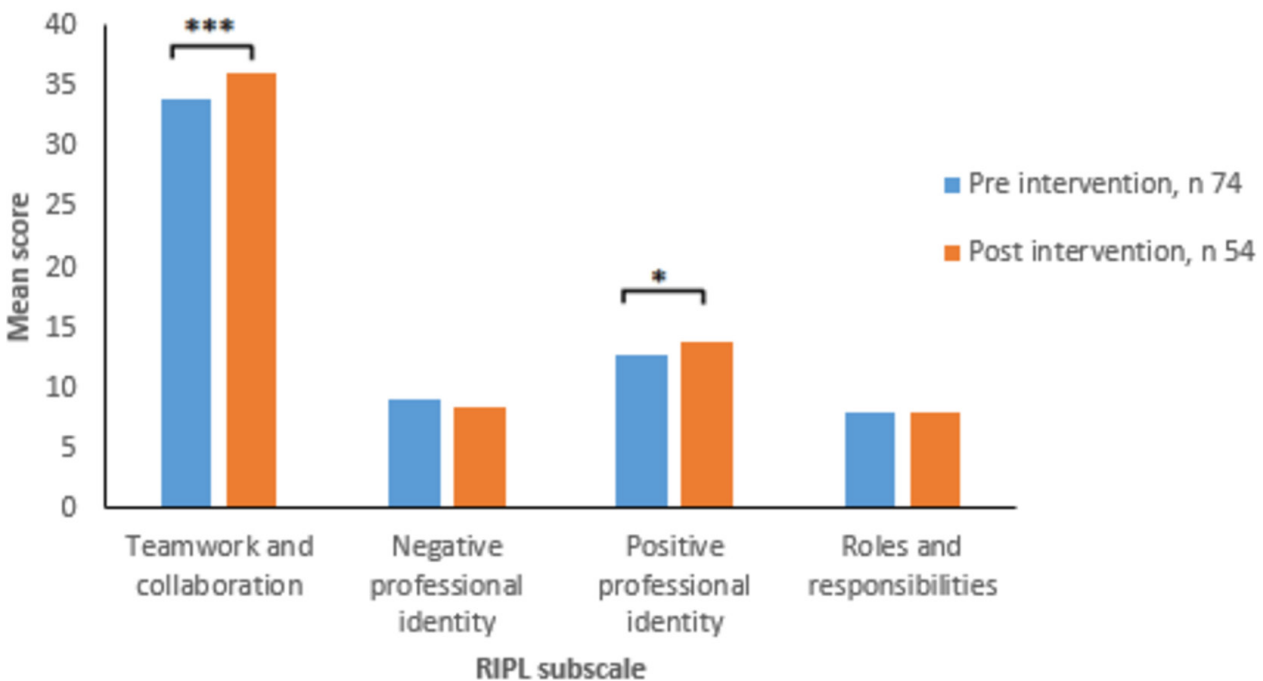

Figure 4 Post-IPE, the medical students in the control group showed statistically significant improvements in two RIPLS subscales: teamwork and collaboration and positive professional identity. IPE, interprofessional education; RIPLS, readiness for interprofessional learning.

The control group scored slightly lower on negative professional identity post-IPE $(\mathrm{M}=8.48, \mathrm{SD}=2.52)$ than pre-IPE $(\mathrm{M}=9, \mathrm{SD}=2.07)$. This difference was not statistically significant $(\mathrm{t}(1.23)=100.42, \mathrm{p}=0.219)$. They also on average differed little on roles and responsibilities $(\mathrm{M}=7.89, \mathrm{SD}=1.69)$ pre-IPE $(\mathrm{M}=7.91, \mathrm{SD}=1.51)$ than post-IPE. This difference was not statistically significant $(\mathrm{t}(.11)=126, \mathrm{p}=0.916)$.

Unexpectedly, the results collected from all medical students show that both the intervention and control groups have the same outcome and this is illustrated in figure 5 .

All feedback forms were assessed for free-text comments.

\section{Open-ended questions and results}

Awareness of roles, expertise and responsibilities (tables 1 and 2): in terms of the actual session, both groups enjoyed getting to know more about the other role's perspective and what they would do in different situations. They

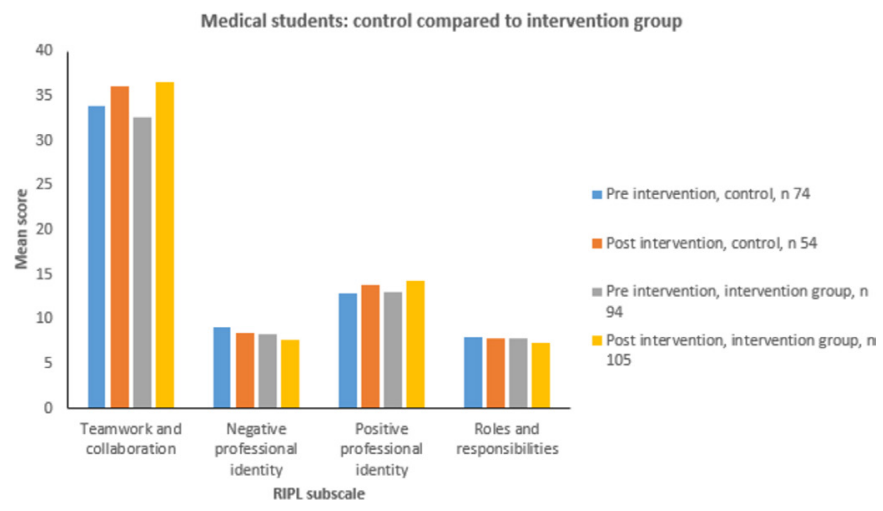

Figure 5 Post-IPE results show that medical students from the intervention and control groups had identical change in the RIPLS subscales. IPE, interprofessional education; RIPL, readiness for interprofessional learning. also enjoyed learning about how they could collaborate with one another. Medical students found IPE improved their understanding of nursing priorities and thinking, and also illustrated the differences in expertise/skills and roles between the two groups. Both groups enjoyed sharing their different experiences.

Nursing students concerns about IPE (tables 1 and 2): prior to the session concerns about learning alongside medical students; they felt intimidated and feared there would be a hierarchy, but IPE appeared to be successful in removing these concerns, with nursing students finding the sessions very open and comfortable who also indicated that they found easy to contribute to the session, and they found the group to be very welcoming and respectful, and the session to be very relaxed. The results of this study also suggest that the nursing students became more confident as a result of the teaching; with some indicating that they would be happier to approach a doctor in the future or share information with them. It would appear that IPE resulted in boosting nursing confidence around their medical peers, and decreased concerns about feelings of inferiority/intimidation. Nursing students suggested that the teaching session highlighted the fact that medical students were not so different to nursing. It is also interesting that post-IPE nursing students appeared to be more specific in defining their own areas of expertise and in some way shifted nursing perspectives of their own expertise, describing more expertise than prior to IPE.

Medical students concerns about IPE (tables 1 and 2) were about working with nursing students being perceived as arrogant, pretentious and condescending prior to the session. During the session, they found it very easy to contribute, regardless of group (intervention or control) and both felt IPE had emphasised the importance of communication. Both professions also felt that teaching had 
Table 1 Qualitative data pre-IPE for the intervention and control groups: awareness of roles, expertise and responsibilities; nursing and medical students' concerns about IPE; curriculum topics

\begin{tabular}{|c|c|c|c|}
\hline \multirow{2}{*}{$\begin{array}{l}\text { Qualitative data } \\
\text { Pre-IPE }\end{array}$} & \multicolumn{2}{|l|}{ Intervention group } & \multirow{2}{*}{$\begin{array}{l}\text { Control group } \\
\text { Medical students }\end{array}$} \\
\hline & Nursing students & Medical students & \\
\hline $\begin{array}{l}\text { Role } \\
\text { (of the 'other') }\end{array}$ & $\begin{array}{l}\text { Doctor: } \\
\text { Diagnosis and treatment of the } \\
\text { patient }\end{array}$ & $\begin{array}{l}\text { Nurse: } \\
\text { Provides practical care } \\
\text { - Provides support for the patient }\end{array}$ & $\begin{array}{l}\text { Nurse: } \\
\text { Provides practical care } \\
\text { Communicates patients' } \\
\text { issues } \\
\text { Implements medical plans } \\
\text { and working with doctors }\end{array}$ \\
\hline Expertise & $\begin{array}{l}\text { Doctor: } \\
\text { - Clinical knowledge }\end{array}$ & $\begin{array}{l}\text { Nurse: } \\
\text { - Patient care and monitoring } \\
\text { - Medical knowledge } \\
\text { - Safeguarding } \\
\text { - Patient comfort } \\
\text { - Patient concerns }\end{array}$ & $\begin{array}{l}\text { Nurse: } \\
\text { Knowledge of patient needs } \\
\text { Practical care and } \\
\text { management } \\
\text { - Communication skills }\end{array}$ \\
\hline
\end{tabular}

IPE, interprofessional education.

improved their knowledge of the roles in the multidisciplinary team (MDT).

In terms of perceptions of each other's role, pre-IPE and post-IPE (tables 1 and 2) views of the doctors' role remained the same across both professional groups and teaching conditions (active vs control). Everyone viewed this role as one focused on diagnosis and treatment, with some clinical decision makings. In terms of the nursing role, nursing students' perceptions also did not change much post-IPE, but more nursing students discussed the fact about the roles and responsibilities for working collaboratively for the best of the patient interests. This was not a common theme among the medical student responses in either the intervention or the control groups. Similar to role, both nursing and medical student perceptions of doctors' expertise did not change much post-IPE. Perceptions of the role very much focused on doctors' medical knowledge and knowledge of treating the patient. Medical student descriptions of nursing expertise also did not appear to change much across either groups or condition. However, as stated earlier, nursing student perceptions of nursing expertise were somewhat more extensive post-IPE.

Curriculum topics: the list created initially pre-IPE by students for the future topics varied a bit, but post-IPE, the most common topics suggested by both groups included working on case scenarios, communication, ethics, the deteriorating patient and emergency situations. What is even more interesting is the fact after teaching some of the control group suggested doctor/nursing roles as a topic for future teaching (tables 1 and 2).

Receptiveness to geriatric IPE: it was received generally in a positive light by both healthcare groups, but slightly more so by nursing students. It appears to have reinforced the 
Table 2 Qualitative data post-IPE for the intervention and control groups; awareness of roles, expertise and responsibilities; nursing and medical students concerns about IPE; curriculum topics

\begin{tabular}{|c|c|c|c|}
\hline \multirow[b]{2}{*}{ Qualitative data post-IPE } & \multicolumn{2}{|l|}{ Intervention group } & \multirow{2}{*}{$\begin{array}{l}\text { Control group } \\
\text { Medical students }\end{array}$} \\
\hline & Nursing students & Medical students & \\
\hline $\begin{array}{l}\text { Role } \\
\text { (of the 'other') } \\
\text { No significant difference } \\
\text { pre-IPE and post-IPE groups } \\
\text { for all }\end{array}$ & $\begin{array}{l}\text { Doctor: } \\
\text { Same as pre-IPE group. } \\
\text { However, much more } \\
\text { appreciation of working with } \\
\text { doctors } \\
\text { Example comment: } \\
\text { 'To support each other (to) } \\
\text { benefit patient' }\end{array}$ & $\begin{array}{l}\text { Nurse: } \\
\text { Same as pre-IPE group. } \\
\text { However, much more } \\
\text { appreciation on the other } \\
\text { nursing roles } \\
\text { Example comment: } \\
\text { 'Patient care and monitoring, } \\
\text { executing management plan, } \\
\text { liaising with the doctors and } \\
\text { other healthcare professionals' }\end{array}$ & $\begin{array}{l}\text { Nurse: } \\
\text { No significant difference pre-IPE } \\
\text { and post-IPE groups }\end{array}$ \\
\hline $\begin{array}{l}\text { Expertise } \\
\text { No significant difference } \\
\text { pre-IPE and post-IPE groups } \\
\text { for all }\end{array}$ & $\begin{array}{l}\text { Doctor: } \\
\text { However, more emphasis } \\
\text { on doctors having much } \\
\text { more in-depth knowledge } \\
\text { of anatomy, physiology and } \\
\text { treatments }\end{array}$ & $\begin{array}{l}\text { Nurse: } \\
\text { However, more emphasis } \\
\text { on nurses' having more } \\
\text { knowledge of the patient and } \\
\text { what is key to their welfare }\end{array}$ & $\begin{array}{l}\text { Nurse: } \\
\text { No significant difference pre-IPE } \\
\text { and post-IPE groups }\end{array}$ \\
\hline Concerns about IPE & $\begin{array}{l}\text { Concerns: } \\
\text { Most expressed they now } \\
\text { had no concerns post-IPE } \\
\text { A few students expressed } \\
\text { ongoing concerns about } \\
\text { difference in knowledge base } \\
\text { Example comments: } \\
\text { 'Not anymore (concerns)' } \\
\text { 'Knowledge difference' }\end{array}$ & $\begin{array}{l}\text { Concerns: } \\
\text { Overall less concerns than pre- } \\
\text { IPE group } \\
\text { Some still believed that } \\
\text { students were starting at a } \\
\text { different level of knowledge, so } \\
\text { different focuses were needed } \\
\text { for each group } \\
\text { Example comments: } \\
\text { 'Some differences in type of } \\
\text { knowledge made it difficult to } \\
\text { work together at points' } \\
\text { 'It feels like a bit of a waste of } \\
\text { time, we have very different } \\
\text { teaching usually with very } \\
\text { different focuses' }\end{array}$ & $\begin{array}{l}\text { Similar results to medical } \\
\text { students from the intervention } \\
\text { group }\end{array}$ \\
\hline
\end{tabular}

IPE, interprofessional education.

importance of collaborative working, with a majority of students believing it had improved their ability to work collaboratively and most stating that they would be happy to participate again (table 3 ).

Expectations of IPE (table 3) varied among the students before the session, but post-IPE, most students expressed positive views and felt that it was more useful than they had expected it to be. Out of both nursing and medical students, nursing students appeared more open to the overall concept of IPE, unlike medical students. Some medical students had higher expectations from the feedback sessions and their learning about the nurses' role. Majority of students in both groups enjoyed this experience, found contribution/voicing opinion during IPE easy and would like to take part in IPE again (table 3 ).
Understanding of interprofessional collaboration (table 3): both groups felt that the teaching enhanced their understanding of interprofessional collaboration and increased their ability to work collaboratively. Nursing students felt their ability had been enhanced through a better understanding of the roles in MDT and the doctor's perspective. Medical students believed their ability was improved through a better understanding of the nursing perspective and indicated they would greatly value the views of other healthcare professionals. Only a minority of students felt it had not increased their understanding or ability.

Future IPE sessions-included comments about better organisation that smaller groups were more effective and some preferred a shorter session (table 3 ). 
Table 3 Qualitative data post-IPE for the intervention and control groups; ease of contribution/voicing opinion during IPE, meeting the expectations from IPE, participating in IPE again, enjoyment in IPE, learning points from IPE, understanding collaboration, the impact of IPE on the ability to work collaboratively

\section{Postintervention questions-regarding experience from IPE and from interacting with nursing/medical student colleagues}

Ease of contribution/voicing opinion during IPE

Expectations of IPE

Taking part again
Nursing students

- Majority found contribution to the group easy/very easy. Some felt this was even easier in small groups

- Nursing students expressed feeling generally comfortable and respected The group was friendly and listened

- A minority felt there were some individuals (profession of those individuals was not stated) that dominated the group

Example comments:

'Very easy, relaxed, no judgement, we all learned'

'Very easy, I felt everyone was interested in what everyone had to say'

- Majority stated it was what they expected

- Few had expected to learn from scenarios, to learn about peers and about how to work well together

- Some did not expect it be so useful and many said it was better than they would have expected

Example comment:

\section{Medical students}

- Majority found contribution easy

- Smaller groups were helpful

- Groups were welcoming and the teaching relaxed

Example comments:

'Very easy, relaxed and inclusive atmosphere'

'Fine, good welcoming people who valued all opinions and we all gained valuable experience from each other' 'Easy-small groups'
'Better, I guessed I wouldn't have a say, but I learnt a lot'

- Majority would be happy to participate again but asked for better organisation, timings and more information in advance

Example comment:

'Yes, found it interesting as different perspective, plus we'll all be working together in the future so good to get an understanding of each other's roles'
- Majority stated it was either as expected or better than expected

- Some expected to learn more about their peers role and their perspective

- Some expected smaller groups

- A minority did not find the feedback session as useful as expected

Example comment:

'Feedback did not target how to work together'

- Majority would be happy to participate again, as it allowed them to learn about nursing responsibility role, experience and expertise

- A few would not participate again. They felt sessions could have been better organised and structured. Some suggested shorter and more time efficient workshops, and changing the format of delivering the sessions

Example comments:

'Yes, in principle, but on more balanced topics- I didn't find this very useful (large groups). Small groups were useful'

'Yes, lovely to meet nursing students and learn what we do and can expect from each other professionally'

Continued 
Table 3 Continued

Postintervention questions-regarding experience from IPE and from interacting with nursing/medical student colleagues

Nursing students

\section{Medical students}

Enjoyment

- Most enjoyed having the opportunity to understand a doctor's perspective and learning about the role of a doctor, in addition to sharing ideas, knowledge and different experiences

- Minority enjoyed thinking about collaboration between the two roles and becoming more self-confident as a result of the teaching session

- Some felt sessions were too long Example comment:

'Liaising about their point of view, being more confident around medical students'

\begin{tabular}{|c|c|c|}
\hline Learning & $\begin{array}{l}\text { IPE helped to define their strengths } \\
\text { and what their area of expertise is. } \\
\text { This included reinforcing for nursing } \\
\text { students that medical students do } \\
\text { not know everything and can have } \\
\text { similar concerns to them } \\
\text { Some indicated they had learnt } \\
\text { more about how to collaborate with } \\
\text { other HCPs and about differences } \\
\text { in training } \\
\text { Example comments: } \\
\text { 'Confidence in what I know and } \\
\text { realising that medics don't know } \\
\text { everything either' } \\
\text { 'Hearing they are also anxious to } \\
\text { qualify' } \\
\text { 'Learnt more about what education is } \\
\text { like for medical students' }\end{array}$ & $\begin{array}{l}\text { Learning in terms of difference in } \\
\text { expertise/skills and roles between } \\
\text { the two } \\
\text { The importance of communication } \\
\text { with other healthcare professionals } \\
\text { and the value of their views and the } \\
\text { value of their views. } \\
\text { Appreciated learning about aspects } \\
\text { of healthcare that they did not knov } \\
\text { about. } \\
\text { Example comments: } \\
\text { '(nurses)know much more about basic } \\
\text { patient care' } \\
\text { 'Very useful to communicate with othe } \\
\text { health care professionals and their } \\
\text { views are very useful' }\end{array}$ \\
\hline Understanding collaboration & \multicolumn{2}{|c|}{$\begin{array}{l}\text { Most nursing and medical students felt positive about the IPE teaching session } \\
\text { and felt it had improved their understanding of both roles and the knowledge } \\
\text { that nurses hold and have emphasised the importance of communication. } \\
\text { They also felt that teaching had improved their knowledge of the roles in the } \\
\text { multidisciplinary team (MDT). } \\
\text { Example comments: } \\
\text { 'Better understanding of each other's role and what we bring to MDT' } \\
\text { 'Given a perspective on what nurses are expected to know' } \\
\text { 'It's nice to hear the thought process of the student nurses, understand better } \\
\text { their reasons to call FY1s!' } \\
\text { 'We can learn from nurses about practical areas that we have less knowledge' }\end{array}$} \\
\hline
\end{tabular}

- Most enjoyed getting to understand the nursing perspective, learning more about the nursing role and hearing about different nursing experiences

- Some mentioned it was helpful to understand nursing priorities and others enjoyed thinking about collaboration between the two roles - Some felt sessions were too long Example comment:

'Seeing their point of view and experience' 
Table 3 Continued

\section{Postintervention questions-regarding experience from IPE and from interacting with nursing/medical student colleagues}

Ability to work collaboratively

\section{Nursing students}

Overall, nurses felt more confident about approaching or communicating with other healthcare professionals Example comments:

'(teaching session)has made me more confident in interacting with other members of the healthcare team' Improved ability to work collaboratively by enhancing their understanding of their role in the MDT and an improved understanding of the 'doctor's' perspective in different scenarios. 'Helped me see the patient condition from their perspective and how they would manage the situation'

\section{Medical students}

The majority stated it improved their ability through a better understanding of the nursing perspective and the role. A minority were did not know if it affected their ability

Example comments: 'Proven it is something I agree with; other medical professionals are essential to work along side with as soon as possible 'Helped me to see the patient condition from their perspective and how they would managed the situations'

'Improved ability to hold constructive discussion with other professionals'

Please note real comments from students are in written in Italics.

IPE, interprofessional education.

\section{DISCUSSION}

This workshop was developed to promote IPE, through better understanding of participants' own and others' professional roles (nursing/clinicians), through observation and exploration of participants' reciprocal perceptions, participating in cooperative learning ${ }^{36}$ and collaborating practice between 'old-timers and newcomers', where more skilled practitioners assist the learner's development beyond their competence. ${ }^{103738}$ The promotion of participants' responsibilities, joint working/ decision-making, interchanging IP knowledge, problemsolving, ${ }^{39} 40$ mutual respect, trust-development based on the knowledge of the role performance, behaviours, attitudes, communication, coordination and negotiation, while working on common geriatric problems that are relevant to both professions, ${ }^{4101441-45}$ were encouraged.

This group-based and case-based IPE replaced the model where students learn exclusively from the instructor, emphasising instead learning closer to realworld settings, based on cooperation, requiring students to work collaboratively. ${ }^{8}{ }^{14}$ However, it was assumed that IPE facilitators possess some key knowledge and skillsin the care of the elderly patients, have the ability to manage diverse expectations. Theywere focused in their preparation for these sessions on the PBL case scenarios, more on encouraging students to ask the right questions in a group context. $^{46}$

The literature describes many methods for delivering IPE to health professionals, regardless of specialty, including attending common courses, IP healthcare team activities, patient simulations and elective live-in placements, ${ }^{444547}$ based on the assumption that IPE-related general principles are applicable to education in geriatric medicine. ${ }^{12}$ Difficulties encountered while setting up IPE in undergraduate geriatrics included the lack of data for selecting the following: optimal students level of clinical experience and education, best teaching methods, most suitable curriculum topics for such teaching, optimal number of students per teaching group, length and number of sessions. Also, other encountered difficulties included the timetabling of large number of students/ staff from three different organisations, securing adequate teaching space and qualified teachers and how best to evaluate the teaching.

About our IPE sessions were based on geriatric case scenarios and allowed close contact between IP tutors from both disciplines and students in groups, who reflected on cases/practice-reflection: a "prerequisite of professional caring' including situated learning. ${ }^{1042} 4849$ The emphasis was on promoting ethical practice, relationship-centred care, collegiality, learning together and also learning about each other, communication including narrative methods, ${ }^{475} 51$ all possibly influencing hidden curriculum. This teaching relied on theories that IPE is based on social, cooperative and collaborative learning, the so-called group model, where learning is created in the interaction/interrelationship with others, related to the formation of clinical judgement, that the knowledge from IPE could be acquired from the faculty and peers, allowing students to gain a view of 'others' professions' by feeling, watching and thinking. ${ }^{52}$ The sessions complied with levels 1 and 2a of the Classification of Interprofessional Outcomes ${ }^{42}$ These results are in accordance with the results of the IPE studies, showing positive reaction of learners to IPE, and improvements in attitudes/perceptions and collaborative knowledge/skills. What is still needed is further evidence about geriatric IPE effect on behaviour, benefit to patients and longer term outcomes. ${ }^{53}$ 
Different disciplines and teamworking bring different philosophies, problem-solving styles and system issues, while working together on a given clinical problem/ scenario as a context for decision-making. Students' work was combined with the input from senior teachers/ practitioners (the intervention groups had the advantage of participating twice with 'other' professionals). This teaching could not ensure that participants would continue to function as 'members of the teams'; it aimed to improve their ability to communicate while emphasising that each profession work is based on the mastery and utilisation of distinct types of expert information, the acquisition of the ability of one profession to understand the judgement, meanings and recommendations of 'others', the 'mastery of differing cognitive and normative maps of different professions'. Teaching pointed towards recognition of the limits of one's own type of knowledge and skill set, and the recognition when to rely on the 'others' as confirmed by student feedback..$^{36545}$

Our medical and nursing students showed gains in RIPLs domains, thereby supporting that there was a true benefit from the experience, correlating to the results from other IPE studies. ${ }^{17}$ The success of this teaching may be also attributed to the nature of geriatrics as a collaborative specialty, and to the educators' collaborative approach (characteristic for geriatrics problem-solving) in all given cases, contributing both to the students' positive attitude and to the positive results of the study. For it is well-known example that nursing-practitioner interactive communication with the team members was commonly reported as enhancing team collaboration and its efficiency. ${ }^{5156}$

Interestingly, the intervention and control groups with medical students only, had similar results with the improvements of the RIPLS scores in the same domains, raising the possibility that the group of geriatric educators when mixed from two different health professions, are capable together to successfully deliver geriatric IPE to the uniprofessional groups of learners via PBL method. This can have important implications for the future practice making IPE delivery simpler. This teaching allowed participants to reflect, correct each other's biases and to see the viewpoint different from their own and for the control group this was also possible, as facilitators represented the 'other discipline'. ${ }^{149} 4057$ Further research is necessary to untangle the impact of geriatric specialty itself from the impact of geriatric IPE, and to look what would happen if the same geriatric IPE is delivered to the different profession (eg, nursing students only), including what impact would such IPE have, if geriatrics is replaced with a different specialty.

IPE had a more positive impact on nursing students, with statistically significant improvements across all aspects of the questionnaire. We speculate that this was probably due to their more extensive clinical experience where they may had already encountered clinical situation needing collaboration between members of the MDT, influencing their perception of their and other professions' roles, being less 'observers', but more 'workers' incorporated in their teams. ${ }^{33} 58$

The immediate outcomes included students' perception of improved ability to work collaboratively, the knowledge, that the 'others' hold and the importance of communication. The majority enjoyed this learning experience.

The free text about nursing students' expectations of IPE before the sessions included concerns about their inadequate knowledge, fear of being undermined, intimidated, judged inferior and not being taken seriously by medical students. Medical students' concerns were about the effectiveness of this learning, as well as that they might appear proud or arrogant to the nursing students, confirming that participants arrived with various assumptions about the other members of the team. ${ }^{14}$ After IPE, nursing students highlighted that medical students were not so different and the majority of all students stated that they now had no concerns about IPE. Few medical students stated that the groups were starting from different knowledge levels/backgrounds or that IPE was happening too early in their training.

During the sessions, almost all found it easy to contribute regardless of group (intervention or control) or profession; IPE matched students' expectations, they enjoyed getting to know more about the other role's perspective, and what they would do in different situations. IPE helped their understanding of IP collaboration, ability to work together, of differences in training and expertise/ skills/roles.

Some students (mainly from the control group) complained about 'long sessions' and organisation; a certain number of these students would not participate further unless the activities were better organised and nursing students did not participate. This was understandable: they needed less time to complete their tasks in the first place, as they were not paired with nursing students.

The majority stated that the workshop met their expectations; a few said that it was more useful than expected. A minority asked for more specific teaching on IP collaboration. The most commonly suggested curricular topics for future IPE sessions were teaching about communication and ethics in geriatrics.

Despite recommendations in the literature for equal numbers from each profession in the participating groups, we could not achieve it. Yet this did not affect the positive outcomes of IPE. The optimal size of the IPE groups of learners is not known: ${ }^{12}$ our results indicate that 10 should be the maximum number in each group, though a few students thought this number was too high. From our experience, we learnt that the groups should have 10 or less than 10 students, as better quality discussion is achieved in smaller groups where every member had a voice that was not lost. A big challenge with organising IPE was the logistics of finding appropriate space.

The unplanned benefit of this teaching included strengthened links through joint work between 
practice-based clinicians and university educators (NHS/ Universities). Overall positive feedback from the students had impact for the future teaching: the new plans for the further development of undergraduate geriatric IPE will also include other students (paramedics and pharmacy) who will join medical and nursing students in the future teaching sessions. The significant changes are to be implemented, as the direct consequences of the results of this study are the inclusion of more clinically experienced Year 6 medical students, instead of Year 4 in future geriatric IPE sessions.

This open and flexible approach by two academic institutions in collaboration with NHS trust staff enabled 'cutting through disciplinary boundaries', ${ }^{14}$ emphasising that it is possible and indeed practicable to combine uniprofessional and IP discourses, so we would recommend this form of IPE for geriatrics, with the expanding of the inclusion of other professions. The results from this teaching may be seen as confirming that the outcomes of IPE delivery in geriatrics are positive, regardless of the form it takes, ${ }^{12}$ possible also due to conveying to the students the skills, knowledge and energy of the geriatric teams and their ability to solve problems. ${ }^{59}$

The limitations of this study include the use of RIPLS scale, and known concerns about it $^{273360-62}$ prompted the use of the modified scale. In the meantime further development and validation of instruments to measure the variety of IP competencies related to IPE continued, giving more options to the researchers compared with the time of planning and conducting our study, and in 2017 a global consensus was reached on IP learning outcomes, as well as guidance on the purpose of the assessments in IPE. $^{3463}$

Statistical analysis was limited by the fact that not all students returned the feedback forms (possibly missing more negative views, but this is less likely as completion was anonymous). However, some students commented that completing both questionnaires was time-consuming, possible contributing to the reduced rate of feedback. The overall number of nursing students was smaller owing to the nursing availability at the JR hospital site; the control group consisted of only medical students for the same reasons. Other limitations are also not distinguishing between graduate and undergraduate entry medical students, possible influencing the study results, as the age and maturity of students is well recognised that can influence learning outcomes. ${ }^{64}$ Also, students had unequal levels of clinical experience at the time of their IPE workshops, with the nursing students having more than the medical students at the time of the workshop, as well as the lack of the involvement of patients and carers in the development of this study ${ }^{66}$. The study was conducted on the PBL case-scenarios, and future work should expand to the clinical practice. The strength of the study is the inclusion of a larger number of participants from both disciplines, the inclusion of the control group and that this was a controlled before-after study.

\section{CONCLUSION}

Our findings have several implications for the undergraduate education in geriatrics. They indicate that some aspects of geriatric medicine can be delivered effectively to nursing and medical students through PBL IPE, if facilitated by educators from both professions. Developing IP skills is difficult with traditional, lecture-based teaching; this project describes one alternative way of delivering such teaching, showing that IPE can significantly improve students' attitudes to working and learning with other professions. This easily replicable teaching method provides a simple means of reinforcing the importance of collaborative working when looking after older patients.

While IPE had a more positive impact on nursing students, medical students had still shown statistically significant improvements in two domains (teamwork and collaboration and positive professional identity), revealing identical results in the intervention and control groups, suggesting that the delivery of geriatric IPE could be simplified and still successfully delivered to the undergraduate students by a mixed group of educators, if they act as members of the IP team, to the uniprofessional groups of learners, via PBL method, 'enabling the professions to learn with, from and about each other'. ${ }^{67}$

Overall, IPE appeared to be successful in addressing some cultural issues that may have acted as barriers to working together, and in allowing groups to understand each other's perspectives, emphasising the importance of each role in MDT. A majority of students (both professions, intervention and control groups) believed the experience had enhanced their understanding of collaboration and their ability to work together, particularly boosting nursing students' confidence in their expertise around their medical peers. This programme demonstrated a simple, easily implementable yet effective means of providing appropriate education in geriatric medicine through IPE to medical and nursing students, applicable in the UK and abroad.

Future research into IPE in geriatrics should investigate the impact if only nursing students act as control group; if it occurs later in medical students' education; if sessions are longer and repeated; if they incorporate exclusively the topics suggested by the majority of students and if delivered in clinical setting. Future research should also investigate what would happen if such teaching were delivered to other professions.

\section{In conclusion}

- Effective undergraduate geriatric interprofessional education (IPE) could be delivered in one session to the group not bigger than 10 students, not requiring equal number of learners from each profession.

- Mixed group of educators successfully delivered IPE to uniprofessional groups of learners via problembased learning method, as intervention and control groups had improved readiness for interprofessional learning scores in the same domains. 
- IPE had more positive impact on nursing students, probably attributable to their more extensive clinical experience before geriatric IPE.

- Geriatric IPE helped resolve some students' concerns; nursing about inadequate knowledge, medical about being perceived as arrogant.

- The most commonly suggested topics for future geriatric IPE sessions were about communication and ethics.

\section{Twitter Gaggandeep Singh Alg @DrGSAlg}

Acknowledgements A. Gardner (medical student) and L Twhittle (nurse) initiated the first pilot IPE project in clinical medicine at the OUH in 2013 and the concept of this IPE. Ms Z Scullard gave continuous support to the project and Ms K Quinlan gave the advise about the evaluation of the project. Funding acknowledgement: The project had a financial support from Health Education England Thames Valley (HEETV). The case studies mentioned were created for teaching purposes and do not represent real patients.

Contributors ST designed the study, acquired data, designed analyses, led the workshops and wrote the paper. KM designed the study, acquired data, designed analyses and wrote the paper. $\mathrm{KB}, \mathrm{HB}$ and $\mathrm{CH}$ acquired data, performed statistical analyses, led the workshops. CM designed the study, acquired data, led the workshops and contributed to the manuscript. LCF designed and performed the statistical analyses and contributed to the manuscript. GSA led the workshops, acquired data and contributed to the manuscript. JB, EP and CFJ led the workshops and acquired data. LW helped with the organisation of the workshops and contributed to the curriculum.

Funding Health Education Thames Valley gave a small grant to support and develop IPE course.

Competing interests ST, CM and LCF were supported by HETV grant.

Patient and public involvement statement There was no patient and public involvement.

Patient consent for publication Not required.

Ethics approval Students consented to participate in this study and had the right to withdraw at any point. This study was approved by the Research Ethics Committees (CUREC); the reference number for this project is MSD-IDREC-C1-2014-027.

Provenance and peer review Not commissioned; externally peer reviewed.

Data availability statement All data relevant to the study are included in the article or uploaded as supplementary information.

Open access This is an open access article distributed in accordance with the Creative Commons Attribution Non Commercial (CC BY-NC 4.0) license, which permits others to distribute, remix, adapt, build upon this work non-commercially, and license their derivative works on different terms, provided the original work is properly cited, appropriate credit is given, any changes made indicated, and the use is non-commercial. See: http://creativecommons.org/licenses/by-nc/4.0/.

\section{ORCID iDs}

Sanja Thompson http://orcid.org/0000-0002-1696-3229

Gaggandeep Singh Alg http://orcid.org/0000-0002-7802-856X

\section{REFERENCES}

1 Nursing\&Midwifery Council (NMC). Standards for education and training. Part 1: standards framework for nursing and midwifery education, 2018. https://www.nmc.org.uk/standards-for-educationand-training/standards-framework-for-nursing-and-midwiferyeducation/

2 General Medical Council (GMC). Barriers and enablers of good practice; 2012. https://www.gmc-uk.org/about/what-we-do-andwhy/data-and-research/research-and-insight-archive/barriers-andenablers-of-good-practice

3 World Health Organization. Framework for action on interprofessional education and collaborative practice, 2010. Available: http://www. who.int/hrh/resources/framework_action/en/
4 Bridges D, Davidson RA, Soule Odegard P, et al. Interprofessional collaboration: three best practice models of interprofessional education. Med Educ Online 2011;16:6035.

5 Institute of Medicine Committee on Quality of Health Care in America. Crossing the Quality Chasm: a new health system for the 21st century. 2001, Washington, DC: National Academy Press

6 Aronson JK, consultant physician and clinical pharmacologist. "Collaborative care" is preferable to "patient centered care". BMJ 2016;353.

7 Schapmire TJ, Head BA, Nash WA, et al. Overcoming barriers to interprofessional education in gerontology: the interprofessional curriculum for the care of older adults. Adv Med Educ Pract 2018;9:109-18.

8 Drinka TJK, Clark PG. Healthcare teamwork: interprofessional practice and education. Praeger, An Imprint of ABC-CLIO, LLC, 2016.

9 Hean S, Dickinson C. The contact hypothesis: an exploration of its further potential in interprofessional education. $J$ Interprof Care 2005;19:480-91.

10 Day J. Interprofessional working: an essential guide for health and social care professionals (nursing and health care practice). Cengage learning EMEA, 2013.

11 Hall P, Weaver L. Interdisciplinary education and teamwork: a long and winding road. Med Educ 2001;35:867-75.

12 Keijsers CJPW, Dreher R, Tanner S, et al. Interprofessional education in geriatric medicine. Eur Geriatr Med 2016;7:306-14.

13 Brown DK, Fosnight S, Whitford M, et al. Interprofessional education model for geriatric falls risk assessment and prevention. BMJ Open Qual 2018;7:e000417.

14 Drinka TJK. Interdisciplinary geriatric teams: approaches to conflict as indicators of potential to model teamwork. Educ Gerontol 1994;20:87-103.

15 Wackerhausen $\mathrm{S}$. Collaboration, professional identity and reflection across boundaries. J Interprof Care 2009;23:455-73.

16 Gellis ZD, Kim E, Hadley D, et al. Evaluation of interprofessional health care team communication simulation in geriatric palliative care. Gerontol Geriatr Educ 2019;40:30-42.

17 Wen A, Wong L, Ma C, et al. An interprofessional team simulation exercise about a complex geriatric patient. Gerontol Geriatr Educ 2019;40:16-29.

18 Gould PR, Lee Y, Berkowitz S, et al. Impact of a collaborative interprofessional learning experience upon medical and social work students in geriatric health care. J Interprof Care 2015;29:372-3.

19 Sheppard KD, Ford CR, Sawyer P. The interprofessional clinical experience: interprofessional education in the nursing home. $J$ Interprof Care 2015;2:170-2.

20 King J, Beanlands S, Fiset V, et al. Using interprofessional simulation to improve collaborative competences for nursing, physiotherapy, and respiratory therapy students. J Interprof Care 2016;30:599-605.

21 Renschler L, Rhodes D, Cox C. Effect of interprofessional clinical education programme length on students' attitudes towards teamwork. J Interprof Care 2016;30:338-46.

22 Williams J, Lakhani N. E-Learning for interprofessional education: a challenging option. $J$ Interprof Care 2010;24:201-3.

23 Kramer-Jackman KL, Sabata D, Gibbs H. Creating an online interprofessional collaborative team simulation to overcome common barriers of interprofessional education. Int $\mathrm{J}$ Health Profession 2017;4:90-9.

24 Suter E, Arndt J, Arthur N, et al. Role understanding and effective communication as core competencies for collaborative practice. $J$ Interprof Care 2009;23:41-51.

25 Council of Heads of Medical Schools and Deans of UK Faculties of Medicine. Position paper: interprofessional education; 2003.

26 Parsell G, Bligh J. The development of a questionnaire to assess the readiness of health care students for interprofessional learning (RIPLS). Med Educ 1999;33:95-100.

27 McFadyen AK, Webster V, Strachan K, et al. The readiness for interprofessional learning scale: a possible more stable subscale model for the original version of RIPLS. $J$ Interprof Care 2005:19:595-603.

28 Cockbain BC, Thompson S, Salisbury H, et al. A collaborative strategy to improve geriatric medical education. Age Ageing 2015;44:1036-9.

29 Specialty training curriculum for geriatric medicine curriculum (amendments 2013), 2010. Available: https://www.jrcptb.org.uk/ documents/2010-geriatric-medicine-amendment-2013

30 Blickem C, Priyadharshini E. Patient narratives: the potential for "patient-centred" interprofessional learning? J Interprof Care 2007;21:619-32.

31 Ajjawi R, Higgs J. Learning to reason: a journey of professional socialisation. Adv Health Sci Educ Theory Pract 2008;13:133-50. 
32 C Schmitz C, Brandt BF. The readiness for interprofessional learning scale: to RIPLS or not to RIPLS? that is only part of the question. J Interprof Care 2015;29:525-6.

33 McGettigan P, McKendree J. Interprofessional training for final year healthcare students: a mixed methods evaluation of the impact on ward staff and students of a two-week placement and of factors affecting sustainability. BMC Med Educ 2015;15:185.

34 Rogers GD, Thistlethwaite JE, Anderson ES, et al. International consensus statement on the assessment of interprofessional learning outcomes. Med Teach 2017;39:347-59.

35 Gale NK, Heath G, Cameron E, et al. Using the framework method for the analysis of qualitative data in multi-disciplinary health research. BMC Med Res Methodol 2013;13:117.

36 Shimazoe J, Aldrich H. Group Work Can Be Gratifying: Understanding \& Overcoming Resistance to Cooperative Learning. College Teaching 2010;58:52-7.

37 Pecukonis E, Doyle O, Bliss DL. Reducing barriers to interprofessional training: promoting interprofessional cultural competence. J Interprof Care 2008;22:417-28.

38 Marks A, Mathieu J, Zaccaro S. A temporally based framework and taxonomy of team processes. Academy of Management Review 2001;3:356-76.

39 Marks MA, Sabella MJ, Burke CS, et al. The impact of cross-training on team effectiveness. J Appl Psychol 2002;87:3-13.

40 Healey MP, Vuori T, Hodgkinson GP. When teams agree while disagreeing: reflexion and reflection in shared cognition. Academy of Management Review 2015;40:399-422.

41 Boet S, Bould MD, Layat Burn C, et al. Twelve tips for a successful interprofessional team-based high-fidelity simulation education session. Med Teach 2014;36:853-7.

42 Hammick M, Freeth D, Koppel I, et al. A best evidence systematic review of interprofessional education: BEME guide No. 9. Med Teach 2007;29:735-51.

43 Freeth D, Reeves SJ. Learning to work together: using the presage, process, product (3p) model to highlight decisions and possibilities. J Interprof Care 2004;22:499-508.

44 Robertson J, Bandali K. Bridging the gap: enhancing interprofessional education using simulation. J Interprof Care 2008;22:499-508.

45 Rodehorst TK, Wilhelm SL, Jensen L. Use of interdisciplinary simulation to understand perceptions of team members' roles. Journal of Professional Nursing 2005;21:159-66.

46 Anderson ES, Cox D, Thorpe LN. Preparation of educators involved in interprofessional education. J Interprof Care 2009;23:81-94.

47 Pelling S, Kalen A, Hammar M, et al. Preparation for becoming members of health care teams: findings from a 5-year evaluation of a student interprofessional training ward. J Interprof Care 2011;25:328-32.

48 Servant VFC, Schmidt HG. Revisiting 'Foundations of problem-based learning: some explanatory notes'. Med Educ 2016;50:698-701.

49 Arnseth HC. Activity theory and situated learning theory: contrasting views of educational practice. Pedagogy, Culture \& Society 2008;16:289-302.
50 Locke A. Developmental coaching: bridge to organizational success. Creat Nurs 2008;14:102-10.

51 Frank JC. Updates in gerontology and geriatrics interprofessional education and team training. Gerontol Geriatr Educ 2019;40:1-2.

52 Clark PG. What would a theory of interprofessional education look like? some suggestions for developing a theoretical framework for teamwork training 1. J Interprof Care 2006;20:577-89.

53 Reeves S, Fletcher S, Barr $\mathrm{H}$, et al. A BEME systematic review of the effects of interprofessional education: BEME guide No. 39. Med Teach 2016;38:656-68.

54 Shon DABass J, ed. Educating the reflective practitioner. San Francisco: CA, 1990

55 Healey MP, Vuori T, Hodgkinson GP. When teams agree while disagreeing: reflexion and reflection in shared cognition. Acad Manage Rev 2015;40:399-422.

56 Hurlock-Chorostecki C, Forchuk C, Orchard C, et al. Hospital-Based nurse practitioner roles and interprofessional practice: a scoping review. Nurs Health Sci 2014;16:403-10.

57 Lattuca LR. Learning interdisciplinarity: sociocultural perspectives on academic work. Journal of Higher Education 2002;73:711-390.

58 Taylor DCM, Hamdy H. Adult learning theories: implications for learning and teaching in medical education: AMEE guide No. 83. Med Teach 2013;35:e1561-72.

59 Drinka T, Ray RO. An investigation of power in an interdisciplinary health care team. Gerontology\&Geriatrics education 1986;6:43-53.

60 Mahler C, Berger S, Reeves S. The readiness for interprofessional learning scale (RIPLS): a problematic evaluative scale for the interprofessional field. J Interprof Care 2015;29:289-91.

61 Kerry MJ, Wang R, Bai J. Assessment of the readiness for interprofessional learning scale (RIPLS): an item response theory analysis. J Interprof Care 2018;32:634-7.

62 Thannhauser J, Russell-Mayhew S, Scott C. Measures of interprofessional education and collaboration. Medical education 2015;49:386-98.

63 Schmitz CC, Radosevich DM, Jardine P, et al. The interprofessiona collaborative competency attainment survey (ICCAS): a replication validation study. J Interprof Care 2017;31:28-34.

64 Anderson ES, Thorpe LN. Early interprofessional interactions: does student age matter? J Interprof Care 2008;22:263-82.

65 Sandover S, Jonas-Dwyer D, Marr T. Graduate entry and undergraduate medical students' study approaches, stress levels and ways of coping: a five year longitudinal study. BMC Med Educ $2015 ; 15$.

66 Anderson ES, Ford J, Thorpe L. Perspectives on patients and carers in leading teaching roles in interprofessional education. $J$ Interprof Care 2019;33:216-25.

67 CAIPE, Centre For The Advancement Of Interprofessional Education. The principles of interprofessional education, 2011. Available: http://caipe.org.uk/news/caipe-has-updated-its-principles-ofinterprofessional-education 